STRUCTURAL SCIENCE CRYSTAL ENGINEERING MATERIALS

ISSN 2052-5206

\section{Earth Materials. Introduction to Mineralogy and Petrology. 2nd edition. By Cornelis Klein and Anthony Philpotts. Cambridge University Press, 2016. Pp. 616. Price GBP 49.99 (ISBN 9781316608852, paperback), GBP 100 (ISBN 9781107155404, hardcover)}

\author{
François Faure*
}

Université de Lorraine, ENSG, Nancy, France. *Correspondence e-mail: francois.faure@univ-lorraine.fr

The second edition is a true introduction to mineralogy and petrology. The book encompasses the fundamental aspects of mineralogy, crystallography, thermodynamics and kinetics; it presents also their related instrumental methods and which processes are involved in the formation of rocks, that is, in essence, petrology. The book is organized in such a way that any new student or researcher to the field can rapidly acquire a lot of knowledge on the main concepts of petrology.

Each chapter begins with a brief abstract and at the end includes a quiz to allow the reader to evaluate if they have understood the main concepts presented. Each chapter contains links to Web sites offering software programs, animations and images of rocks samples (hand specimens and thin sections). Each chapter ends with references for further reading material for a deeper coverage of the subject. An index and a glossary are given at the end of the book for additional references.

This textbook will allow the reader to acquire in a course semester all the basic information needed to describe and understand how rocks form. The background developed in the early chapters (on crystal structures, crystallography, how to used a petrographic microscope...) is dense but the explanations are clear and well illustrated. The authors chose to present the systematic mineralogical description simultaneously with the type of rocks in which these minerals occur. I think that this is a very good idea: by doing so, it will show to the student that in petrology only a limited number of minerals need to be known. The addition of a new chapter (dedicated to thermodynamics and kinetics processes) that did not appear in the first edition will allow the students to understand more the processes involved in the formation of rocks, and how to determine their ages. This new chapter will be fundamental by providing a global view on petrology.

The uses of minerals in commercial applications are outlined throughout the book, and even the penultimate chapter focuses on some selected examples of Earth material resources that are used in everyday life. Finally, the last chapter discusses the beneficial and negative effects these Earth materials can have on human health. Another strength of the book is the high quality of its color illustrations. The photographs in the field, of hand specimens and thin sections are all beautiful and useful.

Overall, I highly recommend this book. By using this book, a student will become rapidly familiar with the discipline by acquiring the majority of skills needed to investigate a wide range of rocks. 